\title{
Capital Deepening, Capacity Utilization and New Drivers of China's Economic Growth
}

\author{
Zhili Ren, Shuoxing Zheng \\ Shannxi Normal University SNNU \\ Xi'an, China
}

\begin{abstract}
According to the production function method, this paper builds a time-varying elasticity production function and use the state space model to estimate the dynamic output elasticity of the get inputs where the capital output elastic shows a downward trend year by year. What is more, in accordance with the declining capacity utilization and phenomenon of excess production capacity, this paper analyses the reason for the capital output elastic decline year by year, and actively cultivates new economic growth momentum and the new growth point to provide high quality of economic growth.
\end{abstract}

Keywords-Time-varying Elasticity; Production Function; Output Elasticity; Capacity Utilization; New Drivers

\section{INTRODUCTION}

Since reform and opening up, China's economy continued for more than 30 years of rapid growth, was once known as the Chinese miracle However, since the mid-1990-s, the Chinese economy on the whole, bid farewell to shortage of seller's market were replaced by a buyer's market, supply exceeds demand become the norm in the economy, the phenomenon of excess production capacity comes, capital utilization rate has been falling, the test of Chinese economic growth continue to slide.

For dynamic analysis of the economic growth, the production function method is one of the most widely used methods, advantage is that with the support of economic theory, from the perspective of supply, the full contribution to economic growth, considering the inputs can contain explain the main factors of economic growth potential. Production function method is used to study in our country's scholars, main Lisheng Shen(1999), Qingwang Guo and Junxue Jia(2004), Meibo Huang and Chaofeng Lv(2010), Hongfei Yu and Yimin Tian (2013), etc. The scholars use the traditional Cobb-Douglas production function, the output elasticity of invariable constant, and only consider the number two elements of capital and labor input, without considering the quality of labour's effect on economic growth. Recent production function method is adopted to improve the economic growth of related research literature Han Guo and Baoping Ren(2014), Guopei Wu Weibin Wang and Xining Zhang(2015), to join the concept of human capital, considering the quality of labour's effect on economic growth, and the traditional production function model is improved, the production function is extended to time-varying fixed elastic production function, more in line with the reality of the economic structure gradually shift in recent years in China.
On the basis of existing literature, this paper established a time-invariable elastic introduced a concept of human capital production function, using the state space model to estimate the dynamic output of material capital and human capital inputs elasticity, capacity utilization and the index into account aims to analyze the index in the role of economic growth, and to further explore the transformation of old and new, kinetic energy, the stability of the long-term economic growth to provide guidance.

\section{MODEL CONSTRUCTION AND DATA DESCRIPTION}

\section{A. Model construction}

In this paper, with the improved Cobb-Douglas production function, and introduced the Lucas (1988) proposed the concept of human capital, the production function contains two kinds of capital: material capital and human capital, these include human capital Cobb-Douglas production function of the general form as follows:

$$
Y_{t}=\mathrm{A} K_{t}^{\alpha_{t}}\left(h_{t} L_{t}\right)^{\beta_{t}}
$$

where $\mathrm{Y}$ is actual output, $\mathrm{A}$ is total factor productivity (TFP), $\mathrm{K}$ is capital input, $\mathrm{h}$ is the quality of labor input and $\mathrm{L}$ is the quantity of labor input. Therefore, $\mathrm{h} * \mathrm{~L}$ represents the meaning of human capital, $\alpha$ and $\beta$ respectively represent the output elasticity of capital and labor. All of the $t$ in the formula is time. Take the logarithm of both ends of the equation (1), and assume that the scale compensation is constant, that is, $\alpha+\beta=1$, and the formula (2) is obtained.

$$
\ln Y_{t}=\ln \mathrm{A}+\alpha_{t} \times \ln K_{t}+\left(1-\alpha_{t}\right) \ln \left(h_{t} L_{t}\right)
$$

$y_{t}=\ln Y_{t}, \mathrm{c}=\ln \mathrm{A}, k_{t}=\ln K_{t}, l_{t}=\ln \left(h_{t} L_{t}\right)$, and then, we can build a state space model.

$$
\begin{aligned}
& y_{t}=\mathrm{c}+\alpha_{t} \times k_{t}+\left(1-\alpha_{t}\right) \times l_{t}+\varepsilon_{t} \\
& \alpha_{t}=\omega+\lambda \times \alpha_{t-1}+\mu_{t}
\end{aligned}
$$

where $y_{t}, k_{t}, l_{t}$ is an observable vector, $\alpha_{t}$ is a state vector. Using Eviews10.0 software, the output elasticity of material capital and human capital can be estimated.

\section{B. Data description}

We selected the national data from 1978 to 2016 to estimate the research, and the data sources and processing methods of specific indicators are as follows: 


\section{1) Real GDP}

First of all, in this paper, according to the new China 55 years statistical data collection, the release of GDP index to calculate the change of the GDP deflator, at the same time as the base period in 1952, set the base of the deflator for 1,1952 through the change of the GDP deflator, in turn, with 1952 as the base period can be computed in deflator, finally with nominal GDP divided by the GDP deflator base (1952) to get real GDP.

\section{2) The Stock of Physical Capital}

In this paper, we use the current perpetual inventory method to calculate the material capital stock in China. $K_{t}=(1-\delta) \times K_{t-1}+I_{t} / p_{t}$, where $K_{t}$ is the actual capital stock of the period $t$ in terms of the constant price of the base year, $I_{t}$ is the amount invested in the current price, $p_{t}$ is the price indices, $\delta$ is the rate of depreciation. We chose fixed capital formation as the investment of the year, for investment price index, we according to the history of China's GDP accounting data $(1952 \sim 1995)$ of China's GDP accounting historical data (1952 2004), calculated with 1952 as the base price deflator. The capital stock of the base period is calculated according to the international common algorithm. $K_{0}=I_{0} /(\mathrm{g}+\delta)$, where $K_{0}$ is the capital stock of base period, $I_{0}$ is amount of investment, $\mathrm{g}$ is the real investment annual growth rate in the sample period, the economic depreciation rate was $10.96 \%$ using the research results of Haojie Shan (2008).

\section{3) The Stock of human capital}

Regarding the number of labor input, this paper adopts the calendar year employment instead of whole society, and because of the statistical system of around 1990, we easily find out that the employment of statistical yearbook published in 1990, before and after the abnormal fluctuations. Therefore, this paper Guopei Wu etc. (2015), the method of the release of employment in the statistical yearbook in 1990 before and after processing, the fluctuations of each year from 1978 to 2016 is obtained after adjusting employment. For the quality of labor force, the average number of years of education was replaced each year, and the average number of years of education in China's employment population from 1978 to 2016 was estimated by Holz (2005).

\section{4) Capacity Utilization}

This paper adopts the method of Weiguo Wang and Jiemin Yuan (2012), and uses AK function to measure capacity utilization. Specific measures set for, aggregate production function as AK function, first of all, the use of the above have been calculated in each of the real GDP and the real capital stock, then the calculation of GDP and the ratio of $\mathrm{K}$, in each of the year will be the biggest ratio as year of capacity utilization rate is $100 \%$, and the calculation is based on the data of the this year A, so as to determine the AK function, and then calculated for each year of capacity utilization.

\section{EMPIRICAL ANALYSIS}

This paper builds a time-invariable elastic production function, to estimate changes over time of capital and labor output elasticity, we estimate using the state space model, this model need variables meet the conditions of the stationary and cointegration, therefore, we first to ADF stationarity test of each data series, the result shows that its order for a single whole sequence; further Johansen cointegration method is used to test whether there is a cointegration relationship between each variable, test results show that there are at least one collaborators integral variable, conform to the requirements of the model, therefore, the use of Eviews10.0 software for type (4), (5) estimation of state space model, variable parameter estimation results are obtained as shown in table 1 :

TABLE I ESTIMATION RESULTS OF VARIABLE PARAMETER $\alpha_{t}$

\begin{tabular}{llllllllll}
\hline year & $\boldsymbol{\alpha}_{\boldsymbol{t}}$ & year & $\boldsymbol{\alpha}_{\boldsymbol{t}}$ & year & $\boldsymbol{\alpha}_{\boldsymbol{t}}$ & year & $\boldsymbol{\alpha}_{\boldsymbol{t}}$ & year & $\boldsymbol{\alpha}_{\boldsymbol{t}}$ \\
1978 & 0.7831 & 1986 & 0.7425 & 1994 & 0.6868 & 2002 & 0.6752 & 2010 & 0.6277 \\
1979 & 0.7819 & 1987 & 0.7380 & 1995 & 0.6813 & 2003 & 0.6736 & 2011 & 0.6286 \\
1980 & 0.7811 & 1988 & 0.7336 & 1996 & 0.6795 & 2004 & 0.6713 & 2012 & 0.6372 \\
1981 & 0.7814 & 1989 & 0.7383 & 1997 & 0.6772 & 2005 & 0.6637 & 2013 & 0.6443 \\
1982 & 0.7754 & 1990 & 0.7395 & 1998 & 0.6804 & 2006 & 0.6488 & 2014 & 0.6501 \\
1983 & 0.7665 & 1991 & 0.7279 & 1999 & 0.6811 & 2007 & 0.6266 & 2015 & 0.6529 \\
1984 & 0.7506 & 1992 & 0.7100 & 2000 & 0.6785 & 2008 & 0.6229 & 2016 & 0.6532 \\
1985 & 0.7410 & 1993 & 0.6970 & 2001 & 0.6776 & 2009 & 0.6292 & &
\end{tabular}

TABLE II STATISTICAL TEST RESULTS FOR VARIABLE PARAMETERS

$\begin{array}{llll}\text { Finnal State } & \text { Root MSE } & \text { Prob. }\end{array}$

$\begin{array}{lllll}\boldsymbol{\alpha}_{\boldsymbol{t}} & 0.6532 & 0.0078 & 83.6437 & 0.0000\end{array}$


The estimation results show that the mean variance of variable parameter $\alpha_{t}$ is very small, indicating that the statistical test results are very significant, indicating that the estimation results of the model are valid. According to the estimation results, it is not hard to see the material capital output elasticity of $\alpha_{t}$ value, showing a downward trend year by year, this shows that with the increasing number of physical capital input, each unit of capital for the contribution of output reduced gradually. On the contrary, the output elasticity of human capital presents a trend of increasing year by year.

In view of the change in the contribution of capital investment to output decreasing year by year, the author

believes that the phenomenon of "overcapacity" in China should be considered. Overcapacity means that the actual production capacity exceeds the market demand and exceeds the normal level of expectation. For excess capacity evaluation mainly based on the capacity utilization (CU), generally considered the normal capacity utilisation rates between $79 \%$ $83 \%$, more than $90 \%$, has the phenomenon of insufficient capacity, less than $79 \%$ May be existed the phenomenon of excess production capacity. The data of capacity utilization obtained by the AK function method is used, as shown in table 3:

TABLE III C CAPACITY UTILIZATION IN CHINA FROM 1978 TO 2016

$\begin{array}{ccccccccccc}\text { year } & \text { CU } & \text { year } & \text { CU } & \text { year } & \text { CU } & \text { year } & \text { CU } & \text { year } & \text { CU } \\ 1978 & 0.8853 & 1986 & 0.9381 & 1994 & 1.0000 & 2002 & 0.8420 & 2010 & 0.6664 \\ 1979 & 0.8793 & 1987 & 0.9371 & 1995 & 0.9851 & 2003 & 0.8169 & 2011 & 0.6364 \\ 1980 & 0.8710 & 1988 & 0.9369 & 1996 & 0.9654 & 2004 & 0.7904 & 2012 & 0.6041 \\ 1981 & 0.8653 & 1989 & 0.9185 & 1997 & 0.9491 & 2005 & 0.7741 & 2013 & 0.5766 \\ 1982 & 0.8775 & 1990 & 0.9135 & 1998 & 0.9170 & 2006 & 0.7675 & 2014 & 0.5544 \\ 1983 & 0.8985 & 1991 & 0.9429 & 1999 & 0.8949 & 2007 & 0.7678 & 2015 & 0.5367 \\ 1984 & 0.9392 & 1992 & 0.9862 & 2000 & 0.8808 & 2008 & 0.7411 & 2016 & 0.5222 \\ 1985 & 0.9569 & 1993 & 0.9991 & 2001 & 0.8611 & 2009 & 0.6977 & & \end{array}$

Data source: this paper calculates

We can clearly see from 1978 to 2016, capacity utilization in our country on the whole present a downward trend, capacity utilization decline year by year, since 1995 has declined even to only about $50 \%$, according to the general thought of the normal capacity utilisation rates between $79 \%$ $83 \%$ rules, shows that since 2005 in our country exists the phenomenon of excess production capacity.

Existing literature in the use of production function to calculate potential output as well as the potential growth rate, material capital stock is used for calculation, and the processing method can bring error because of two reasons, on the one hand, the use of new material and old material capital efficiency, a new physical capital efficiency will be high; On the other hand, idle capital is also counted in the capital stock, but this capital is not actually involved in the production process and should not be included in the capital use data in the production function. As a result, as estimated above, the contribution of capital investment to economic growth is substantially underestimated.

That said, although the absolute sense, capital investment are increasing every year in our country, however, if the capacity utilization into account, can be seen from the above capacity utilization data, capital input by effective use of capital in reducing year by year, idle phenomenon to some extent, it is the capital.

On the contrary, it can be seen from the estimation results that the output elasticity of human capital $\beta_{t}$ is increasing year by year, that is to say, the promoting effect of human capital stock on economic growth is increasing year by year. This is in line with the concept of new drivers of economic growth. Early scholars, using production function to study, only consider the effect of population on economic growth, this belongs to the category of old kinetic energy, and this paper consider the concept of human capital for the population quality, it belongs to the category of the new kinetic energy, and its positive role for economic growth and it is not hard to explain. Therefore, active investment in education should be encouraged to accumulate more human capital so as to achieve sustained economic growth.

New kinetic energy is the driving power of economic growth and energy, from the practice of economic development in our country, capital and labor, production factors such as investment and consumption are important factors to promote economic growth in China for a long time, can not be ignored. These elements in the role of promoting economic growth, however, is conditional limit and unsustainable, physical capital and the output elasticity of sharp decline will herald a capital and labor, the role of consumption to promote economic growth is gradually weakening, that is to say, in the industrial structure optimization, in the process of economic development mode change must cultivate a new momentum of economic development, so as to promote the high quality of economic growth. 


\section{CONCLUSIONS AND POLICY RECOMMENDATIONS}

In this paper, by building a time-varying elasticity production function, and using the state space model, first of all, estimate the dynamic factors of material capital and human capital output elasticity, and then, using AK function method, to calculate the capacity utilization of calendar year from 1978 to 2016 in China, and considering the low capacity utilization overcapacity problem brought by the frame realistic effects on economic growth, and vigorously develop new momentum for economic growth at the present stage of China. The main conclusion is: from the absolute sense, material capital stock on economic growth pull role decline year by year, relative to character, the stock of human capital on economic growth pull role to rise year by year.

Therefore, in the study of economic growth, first of all, we should not only consider the material capital stock in the sense of absolute quantity, but also consider the problem of capacity utilization ratio and overcapacity. Second, we should strengthen scientific and technological innovation and personnel training, increase investment in science and technology and education, and raise the level of science and technology and the quality of human capital. Third, we need to focus on improving total factor productivity, transform the old and new drivers of growth under the new normal, and foster new drivers of economic growth. Old kinetic energy in promoting economic growth has been very weak, if still rely on old kinetic energy is difficult to achieve sustainable and healthy economic development, at the same time, with the factor prices, resources and environment constraints, only depend on the quantity expansion and denotative development already did not have the resources and support elements., of course, also want to see, the old and new kinetic energy transformation does not mean discarding old kinetic energy, but in the old system of kinetic energy into the new kinetic energy, make part of the kinetic energy of the old life, and become the new growth point for economic development.

\section{REFERENCES}

[1] Lisheng Shen. Estimation of the change trend of China's potential economic growth rate $[\mathrm{J}]$. Research on quantitative economy, 1999(12):3-6.(In Chinese)

[2] Qingwang Guo, Junxue Jia. Estimation of China's potential output and output gap [J]. Economic research,2004(05):31-39. (In Chinese)

[3] Meibo Hunag,Zhaofeng Lv.Estimation of China's potential output and test of "natural rate hypothesis" [J].Research on quantitative economy, technology and economy,2010,27(07):3-20. (In Chinese)

[4] Hongfei Yu,Yimin Tian. Reestimation of potential output and output gaps in China from 1978 to 2011--based on different production function methods [J]. Financial science,2013(05):85-94. (In Chinese)

[5] Han Guo,Baoping Ren. Structural change,factor output elasticity and China's potential economic growth rate [J].Quantitative economy,2014,31(12):72-84. (In Chinese)

[6] Guopei Wu,Weibin Wang,Xining Zhang.Analysis of China's economic growth potential under the new normal [J].Financial research,2015(08):46-63. (In Chinese)

[7] Haojie Shan. Reestimation of China's capital stock K: 1952-2006 [J]. Research on quantitative economy and technology economy,2008,25(10):17-31. (In Chinese)

[8] Weiguo Wang, Jiemin Yuan.Estimation model of China's capacity utilization rate and its application [J].Statistics and decision-making,2012(20):82-84. (In Chinese)

[9] Holz A.2005,"The Quantity and Quality of Labor in China 1978-2000-2025.”,Working paper. 